Geopolítica(s) Revista de estudios sobre espacio y poder ISSN: 2172-3958

\title{
La Ley de Semillas en Argentina: la disputa por el control y el futuro de la agricultura ${ }^{1}$
}

\author{
Nicolás A. Trivi ${ }^{2}$
}

Recibido: 25 de agosto de 2015 / Aceptado: 15 de noviembre de 2015

Resumen. Desde la llegada de la revolución bioteconológica en la agricultura mundial, las corporaciones semilleras-agroquímicas han avanzado en el control del mercado internacional de alimentos, a partir de diversos mecanismos, entre ellos el de la legislación de derechos de propiedad intelectual. En América Latina, distintos gobiernos han procurado adecuar la legislación nacional a estas tendencias internacionales, con resultado dispar, ya que se ha generado una fuerte resistencia desde organizaciones populares. Argentina, un país de temprana inserción en el mercado internacional de alimentos y de rápida adopción de los derechos de obtentor, está atravesado hoy por una nueva fase de esta disputa, ante la posible sanción de una nueva Ley de Semillas, en la que empresa estadounidense Monsanto está involucrada. Este trabajo hace un repaso del panorama actual desde un punto de vista geográfico, prestando especial atención a las estrategias de las organizaciones que se oponen a la nueva legislación.

Palabras clave: Argentina; propiedad intelectual; agricultura; territorio; movimientos sociales.

\section{[en] The Seed Law in Argentina: The Dispute for the Control and Future of Agriculture}

\begin{abstract}
Since the arrival of the biotechnology revolution in global agriculture, seed-agrochemical corporations have made progress in controlling the international food market, from various mechanisms, including the laws of copyright. In Latin America, various governments have tried to adapt national legislation to these international trends, with mixed results, as it has generated strong resistance from popular organizations. Argentina, a country of early insertion into the international food market and rapid adoption of plants breeders' rights (PBR), is now going through a new phase of this dispute, because of the possible adoption of a new Law on Seeds, where US company Monsanto is involved. This paper gives an overview of the current situation from a geographical point of view, paying special attention to the strategies of the organizations that oppose the new legislation.
\end{abstract}

Keywords: Argentina; intellectual property; agriculture; territory; social movements.

1 Se agradecen a Fernando Frank los aportes y sugerencias en la redacción final del texto.

2 Departamento de Geografía de la Universidad Nacional de La Plata (Argentina)

E-mail: nicolastrivi@yahoo.com.ar 


\title{
[pt] A Lei de Sementes na Argentina: o diferendo sobre o controlo e o futuro da agricultura
}

\begin{abstract}
Resumo. Desde a chegada da revolução biotecnológica na agricultura mundial, corporações de sementes de agroquímicos têm feito progressos no controle do mercado internacional de alimentos, a partir de diversos mecanismos, incluindo a legislação de direitos de propriedade intelectual. Na América Latina, vários governos têm procurado adaptar a legislação nacional em conformidade com estas tendências internacionais, com resultado díspar, como ele foi gerado uma forte resistência por parte de organizações populares. Argentina, um país de inserção precoce no mercado internacional de alimentos e a rápida adoção dos direitos do obtentor, é atravessada hoje para uma nova fase do presente litígio, antes da eventual sanção de uma nova lei de sementes, em que uma empresa americana Monsanto está envolvido. Este artigo faz uma revisão das atuais paisagem a partir de um ponto de vista geográfico, prestando especial atenção às estratégias de organizações que se opõem à nova legislação.
\end{abstract}

Palavras-chave: Argentina; propriedade intelectual; agricultura; território; movimentos sociais.

Sumario. Introducción: la biotecnología y los derechos de propiedad intelectual como territorio inmaterial del agronegocio. 1. Los escenarios de conflicto en América Latina. 2. La situación de Argentina. 3. La oposición popular a la nueva Ley de Semillas: la búsqueda de alternativas, de la resistencia en el territorio a la disputa institucional. 4. Algunas reflexiones finales. Bibliografía.

Cómo citar: Trivi, Nicolás A. (2016) "La ley de semillas en Argentina: la disputa por el control y el futuro de la agricultura”. Geopolítica(s). Revista de estudios sobre espacio y poder, vol. 7, núm. 1, 57-75.

\section{Introducción: la biotecnología y los derechos de propiedad intelectual como territorio inmaterial del agronegocio}

Es sabido que, a lo largo de su evolución, el capitalismo ha reorganizado permanentemente las lógicas productivas de las actividades económicas urbanas y rurales, en un proceso de “destrucción creativa” que reconfigura de manera constante los espacios sociales a distintas escalas en aras de asegurar la reproducción del capital como relación social y como relación entre la sociedad y la naturaleza. Se trata, claro está, de un proceso atravesado por distintos grados de violencia material y simbólica, ya que conlleva la imposición de determinadas relaciones de poder y de producción - así como de saberes y formas de entender y transformar el mundo-, por encima de las relaciones sociales, lógicas productivas y culturas preexistentes. Es también un mecanismo de constante expansión, que permite dar solución a las crisis cíclicas de superproducción sin poner en riesgo los intereses de la burguesía en su conjunto (Harvey, 2005a).

La agricultura y las actividades agropecuarias en general han sido un pilar de este proceso, siendo progresivamente penetradas por las relaciones de producción capitalistas y manifestando las sucesivas etapas de su evolución como modo de producción. Cada fase del capitalismo, en su carrera por convertirse en sistema de alcance global, se ha caracterizado por generar modalidades específicas de la producción agropecuaria, que involucran prácticas organizativas, actores sociales, tecnologías, y formas de regulación determinadas, articulándose también a través de la relación centro-periferia, la cual ha dado pie a formaciones socioespaciales en los países desarrollados y subdesarrollados aparentemente contrapuestas pero dia- 
lécticamente ligadas. A grandes rasgos, y pecando de simplificar demasiado, se puede decir que a la gran plantación esclavista y la desarticulación de la economía feudal que acompañan el surgimiento del capitalismo les siguieron el latifundio extensivo y la mecanización de la segunda revolución industrial; luego la revolución verde atravesó la segunda posguerra y la crisis del petróleo en los años setenta; y, por último, el agronegocio y la revolución biotecnológica se corresponden con la globalización neoliberal.

Es preciso entender estas sucesivas etapas en términos de producción de territorios determinados; es decir, como procesos de territorialización de actores y lógicas productivas que desterritorializan, desplazan formas alternativas de producción agropecuaria, en buena medida gracias a la utilización de nuevas tecnologías de comunicación y transporte, y a las relaciones cada vez más profundas con el capital financiero internacional. Y además este análisis requiere captar la dimensión simbólica que le es inherente, en la medida en que no se puede comprender del todo esta situación sin tener en cuenta que esta producción de territorios abarca la imposición de saberes y conocimientos acordes. O sea, la producción de territorios se da también en el ámbito inmaterial de la producción de saberes, de conocimientos agropecuarios, y de la generación de hegemonía alrededor de supuestos políticos e ideológicos que justifican y son parte de las prácticas de dominación de la burguesía sobre el conjunto de la sociedad (Fernandes, 2009).

En este sentido sostenemos que el actual período de la historia del capitalismo conocido como globalización tiene como manifestación en la producción agropecuaria al modelo del agronegocio: un determinado esquema de organización de la producción de alimentos en el que el capital financiero y las grandes corporaciones adquieren un rol clave, inédito hasta ahora. Un esquema que instrumenta una producción de territorios de nuevo tipo, que la distingue de etapas previas, y que ha generado todo un cuerpo de conocimientos específico, que aseguran su despliegue. Este verdadero territorio inmaterial del agronegocio, que ha penetrado buena parte de los círculos académicos a nivel mundial, y se ha proyectado en los organismos internacionales como la Organización Mundial del Comercio (OMC) y la Organización de las Naciones Unidas para la Alimentación y la Agricultura (FAO), tiene dos pilares fundamentales: por un lado, el científico, en el que se destaca la biotecnología como disciplina relativamente reciente en el campo de las ciencias exactas y naturales, que ha permitido nuevos avances en la manipulación genética de las especies vegetales, y, por otro, el jurídico, en el que la legislación de protección de la propiedad intelectual legitima a nivel legal estos avances científicos, convirtiéndolos en un mecanismo de apropiación de la biodiversidad agrícola por parte de las corporaciones (Perelmuter, 2013). Y más allá de estos dos pilares, están los mecanismos de difusión del agronegocio a través de medios de difusión y think thanks financiados por las propias corporaciones biotecnológicas, de maquinaria, etcétera.

La noción de territorio inmaterial (Fernándes, 2009) permite entender que la producción de conocimiento y de legislación no es una actividad neutral en términos políticos y sociales, sino que implica una relación de poder en la afirmación de intereses económicos y políticos determinados. Aquí, la revolución biotecnológica significó un salto cualitativo en la manipulación de las especies vegetales para asegurar mayores rendimientos agrícolas, ampliando los alcances de la revolución verde de las décadas previas; y al mismo tiempo, permitió una concentración monopólica de estos nuevos eventos genéticos, en un puñado de corporaciones de la 
industria semillera. Es una lógica que podemos asimilar con el concepto de arte de la renta de David Harvey (2005b), en la medida en que implica una dialéctica entre la necesidad del capital de apropiarse de algo único e irrepetible para crear valor (en este caso, especies vegetales) y la necesidad de estandarizarlo para completar su realización en tanto mercancía. A su vez, los avances científicos en esta materia requieren de un respaldo legal que aseguren su plena utilidad en la estrategia de reproducción ampliada del capital. Ahí es donde entra en juego la legislación de protección de la propiedad intelectual, que tuvo una primera etapa en la creación del derecho de obtentor (convenio de la Unión para la Protección de Obtenciones Vegetales del año 1978, conocido como UPOV '78) y luego ha pretendido instalar progresivamente la figura del patentamiento (convenio de la UPOV de 1991, conocido como UPOV '91). Y hablamos de territorio porque esta producción intelectual y legal completa sus objetivos en la medida en que desplaza otras formas de conocimiento, otras propuestas teórico-políticas y prácticas agronómicas, así como reemplaza u obtura legislaciones alternativas.

\section{Los escenarios de conflicto en América Latina}

El subcontinente latinoamericano es una región que históricamente se ha integrado de manera subordinada al mercado internacional, aportando principalmente materias primas claves para el surgimiento y posterior desarrollo del capitalismo como modo de producción de alcance mundial. A lo largo de su historia económica y social ha sufrido profundas transformaciones territoriales, no exentas de conflictos sociales de gran envergadura. En la actualidad, en distintos países latinoamericanos se está experimentando el avance del agronegocio, a través de las nuevas legislaciones de patentamiento del patrimonio genético de las variedades vegetales con valor agrícola. Se trata de una expresión más de la liberalización de la economía que proponen los tratados de libre comercio de los años noventa, como el Tratado de Libre Comercio de América del Norte (TLCAN, conocido como NAFTA, que agrupa a Canadá, Estados Unidos y México), o los nuevos Tratados de Libre Comercio impulsados por el imperialismo estadounidense luego de la derrota política del ALCA en la Cumbre de las Américas del año 2005.

El caso mexicano resulta siempre de interés, como era de esperarse teniendo en cuenta la conocida frase de García Naranjo (“¡Pobre México, tan lejos de Dios y tan cerca de Estados Unidos!”), ya que este país ha sido campo de experimentación directo de las tendencias agrícolas venidas del Norte desde la época de la Revolución Verde. En México, actual firmante del acuerdo UPOV ‘78, en 2005 y 2007 se aprobaron sendas leyes (la de Bioseguridad y Organismos Genéticamente Modificados, y la Federal de Producción, Certificación y Comercio de Semillas), que han buscado allanar el camino para la introducción de maíces transgénicos controlados por las multinacionales semilleras-agroquímicas, nada menos que en el país que es la cuna del maíz. El fuerte arraigo territorial de las innumerables variedades locales ha sido sostén para que las organizaciones populares, campesinas y urbanas, hayan impedido por el momento la aplicación de los aspectos más agresivos de estas leyes. Sin embargo, el fuerte lobby de las empresas semilleras-agroquímicas en el aparato mediático, institucional y científico no descansa, obligando a entidades como la Red en Defensa del Maíz (que aglutina a productores, militantes barriales 
y científicos) y el Tribunal Permanente de los Pueblos a llevar adelante una fuerte campaña de concientización para combatir también propuestas de resultados ambiguos como la de registro y certificación de las variedades nativas (Montecinos, Vélez y Rodríguez Cervantes, 2014).

Colombia es tal vez el caso paradigmático de la virulencia que pueden alcanzar este tipo de disputas en la región, demostrando que la avanzada por el patentamiento de las variedades agrícolas no implica simples litigios legales, sino que supone una lucha directa por los territorios rurales latinoamericanos, y por extensión por la alimentación de la población en general. El país más septentrional de Sudamérica ha jugado un rol clave como aliado estratégico de Estados Unidos, recibiendo enormes cantidades de dinero con motivo de la lucha contra el narcotráfico y las guerrillas, con la contraparte necesaria de ser un laboratorio de políticas neoliberales que han encontrado mayor resistencia en otros lugares del continente. A partir de la aprobación del convenio UPOV '78 por parte de la Comunidad Andina de Naciones, sucesivas legislaciones abrieron camino a los intereses de las multinacionales, en 2005 autorizando la introducción de transgénicos; en 2006 criminalizando la siembra sin autorización; y sobre todo en 2010 con la resolución 9.70 del Instituto Colombiano Agropecuario, que habilitó la persecución de productores y el decomiso de toneladas de arroz que no se correspondían con las variedades súbitamente autorizadas, que casualmente son las que controlan las compañías extranjeras, sin que hubiera demostración alguna de sus ventajas productivas o nutritivas por encima de las variedades criollas. El corolario de la andanada de leyes fue la ley 1518/12 de abril de 2012, que pretendía adecuar la legislación nacional al convenio UPOV '91 para cumplir con los requisitos del TLC firmado con EE UU. La iniciativa de numerosas organizaciones del país logró que la Corte Constitucional colombiana declarara inexequible la ley 1518 a fines de ese mismo año, mientras que el Paro Agrario de 2013 contra la resolución 9.70 y todas las leyes de propiedad intelectual sobre las variedades vegetales alcanzó repercusión nacional, al punto de encontrar respaldo social incluso en los estadios de fútbol (Fútbol Rebelde, $2 / 9 / 2013)^{3}$.

La presión por la ampliación del acuerdo UPOV '91 a otros países de América Latina se ha manifestado en Chile, donde a partir del TLC firmado con Estados Unidos en 2003 ha habido diversas iniciativas parlamentarias para profundizar el control empresarial sobre las variedades de uso agrícola. Todas las propuestas que se han presentado desde el primer gobierno de Michelle Bachelet han encontrado una creciente oposición de parte de las organizaciones campesinas, quienes han conseguido el apoyo de ciertos sectores del Parlamento chileno. En un país con una fuerte impronta conservadora en todas sus instituciones, herencia de la prolongada dictadura pinochetista, el sector social que ha logrado los mayores niveles de movilización e incidencia en el debate público durante los últimos años ha sido el movimiento estudiantil (secundario y universitario), y éste ha sido un eslabón clave para que la lucha de las organizaciones rurales haya llegado a las grandes ciudades y a las organizaciones urbanas, importante para alcanzar mayores niveles de difusión y de articulación política. En la actualidad la última iniciativa para adecuarse

“Colombia: hinchadas con el paro agrario y popular”, Fútbol Rebelde, 2/9/2013. [Puesto en línea el 2 de septiembre de 2013. URL: http://futbolrebelde.blogspot.com.ar/2013/09/colombia-hinchadas-con-el-paroagrario.html. Consultado el 12 de febrero de 2015]. 
UPOV '91 ha sido retirada del proceso legislativo, pero ello no significa que el riesgo de una nueva intentona privatizadora haya desaparecido.

El caso guatemalteco, al igual que el chileno, demuestra que la resolución de este tipo de conflictos depende en gran medida de la correlación de fuerzas entre las distintas clases sociales y sus fracciones, una correlación que es esencialmente dinámica y evoluciona a partir de las distintas estrategias territorializadoras de los actores en pugna. El país centroamericano, que ratificó su pertenencia al CAFTA (TLC con Estados Unidos, República Dominicana, El Salvador y Honduras) en 2005, tiene un alto porcentaje de población aborigen. Y es desde esos sectores que ha surgido la mayor resistencia a una ley de protección de obtentores vegetales conocida popularmente como "Ley Monsanto", la cual fue aprobada en junio de 2014 y derogada en septiembre de ese mismo año, como consecuencia directa de un fuerte proceso de movilización popular (Panampost, 9/9/2014) ${ }^{4}$.

El carácter estratégico de este tipo de cuestiones, y su relación directa con los distintos proyectos sociales que atraviesan la geopolítica del continente, se puede comprobar en el caso de Paraguay. Con posterioridad al golpe de Estado institucional del año 2012 contra el presidente Lugo, quien más allá de sus limitaciones había significado un breve impasse en la hegemonía sin fisuras de la clase dominante, se dio vía libre a la introducción de nuevas variedades transgénicas, se creó un instituto de investigación agrotecnológica con fuerte control del empresariado sojero, y se ha aprobado una ley fitosanitaria que permite el uso indiscriminado de agrotóxicos en la fumigación de los campos. No es casualidad ya que se trata de uno de los países donde, junto con Argentina y Brasil, el monocultivo de soja transgénica ha penetrado con mayor fuerza en la estructura agraria. De esta manera, se refuerza la alianza entre la tradicional oligarquía terrateniente vernácula y el capital trasnacional que impulsa el modelo de los agronegocios a escala global.

En aquellos países donde, como consecuencia de crisis institucionales y políticas muy profundas — que alcanzan el status de auténticas crisis de hegemonía-, se han desencadenado procesos de participación popular de gran envergadura, la cuestión de la legislación sobre las semillas y las variedades de interés agrícola acompaña los vaivenes de una dinámica social para nada lineal y predecible. En el caso de Ecuador, donde rige una ley de semillas acorde a los parámetros de la Revolución verde desde el año 1978, la reforma constitucional de 2008 — que surgió de la autodenominada Revolución ciudadana - asegura el derecho a la libre circulación de semillas, rescata los saberes ancestrales y la conservación de la agrobiodiversidad, y prohíbe la introducción de variedades transgénicas. Sin embargo, desde el gobierno nacional no se ha aprobado una nueva ley de semillas que profundice los posicionamientos de la reforma constitucional, aún cuando desde 2012 hay un proyecto de ley elaborado por la Conferencia Plurinacional de Soberanía Alimentaria. Y, en cambio, en sintonía con su giro burocrático y desmovilizador, el gobierno de Rafael Correa pretende avanzar en el registro y control de las semillas, en la introducción de semillas híbridas y en la autorización de cada vez más variedades transgénicas.

4 “Congreso de Guatemala derogó la polémica Ley Monsanto”, Panampost, 9/9/2014. [Puesto en línea el 9 de septiembre de 2014. URL: http://es.panampost.com/belen-marty/2014/09/09/congreso-de-guatemala-derogola-polemica-ley-monsanto/. Consultado el 5 de febrero de 2015]. 
En Venezuela, un país con problemas históricos de autoabastecimiento alimentario, donde el chavismo ha lanzado un proceso de transformación radical de la sociedad y del aparato estatal —no libre de contradicciones-, existe un debate entre un proyecto de ley de semillas de un grupo de diputados oficialistas que abre la puerta a la introducción de transgénicos, y la propuesta de una nueva ley de semillas que tenga como sustento el concepto de soberanía alimentaria e impida la introducción de variedades modificadas genéticamente, de parte de la militancia de base chavista, a través de la campaña "Venezuela Libre de Transgénicos". Se trata de una cuestión estratégica teniendo en cuenta el panorama de desabastecimiento que intenta generar la derecha golpista aliada del imperialismo y con fuertes contactos con el paramilitarismo colombiano. Por otro lado, la disputa entre los dos proyectos, representativos de distintos sectores del chavismo, se da en el contexto de puesta en marcha del denominado Estado Comunal, un intento de transformación del aparato institucional del Estado venezolano que cristalice y vuelva irreversibles los avances de la Revolución bolivariana.

Este breve repaso, que no agota la totalidad de casos de interés, permite ver que en la región se está dando una fuerte disputa por el control de las variedades agrícolas. Se trata de una batalla política de largo aliento, en la que están en juego formas de organización de la producción de alimentos, con la consecuente territorialización de actores y prácticas determinadas, así como las distintas concepciones sobre la agricultura, el conocimiento científico y los saberes tradicionales. Es una contienda que se despliega en los espacios rurales, pero también en el espacio público de las sociedades latinoamericanas. Y en el Estado, considerado como expresión de una correlación de fuerzas sociales, como un espacio institucional objeto de la territorialización de las clases sociales.

\section{La situación de Argentina}

La problemática de la tierra y la disputa por la apropiación de la enorme riqueza natural del suelo, tensionadas por la relación con el mercado mundial, son constitutivas de la conformación del Estado argentino moderno. La inestabilidad política posterior a la independencia formal del Imperio español en 1816 se debió en gran medida a un enfrentamiento por los beneficios de la exportación de materias primas agropecuarias a través del puerto de Buenos Aires. Mientras tanto, la posterior consolidación del Estado nacional se basó, entre otros elementos, en el genocidio perpetrado sobre los pueblos pampeano-patagónicos y chaqueños, una campaña militar que propició la incorporación de gigantescas extensiones de tierra a la producción principalmente de ganadería ovina, en manos de un selecto grupo de familias oligárquicas. La autodenominada "Campaña del Desierto" se trató además de una operación para liberar los fértiles suelos de la región pampeana para la producción agrícola y la ganadería bovina, con razas de mayor calidad importadas del Reino Unido. Así se completa un panorama de inserción relativamente temprana en el mercado mundial, con una rápida penetración de las relaciones de producción capitalistas en el agro argentino, comandada por una clase dominante que a lo largo de la historia se demostrará muy abierta a incorporar novedades tecnológicas y organizativas para aumentar su rentabilidad, pero reticente a permitir una diversifi- 
cación del aparato productivo nacional que otorgue mayores márgenes de independencia económica en el concierto internacional.

Tal como señala Tamara Perelmuter (2014), ya desde los años treinta del siglo XX existe en Argentina legislación nacional que trata la cuestión del mejoramiento genético de las variedades vegetales, y desde mediados de siglo, con la fundación del Instituto Nacional de Tecnología Agropecuaria (INTA) en 1956, los avances de la todavía incipiente Revolución verde dispondrán de resortes dentro del aparato del estado para desplegarse en el país. Este rumbo se profundizará con la sanción de la Ley de Semillas y Creaciones Fitogenéticas n ${ }^{0} 20.247$ en 1973, vigente hasta la actualidad, que establece mecanismos de identificación y fiscalización de las semillas, pero garantiza el derecho al uso propio de la semilla por parte del productor.

Durante los años noventa, época de reestructuraciones económicas y sociales de gran envergadura, una batería de medidas de cuño neoliberal alentarán un avance significativo del agronegocio a nivel institucional y productivo. En primera instancia, hay que señalar los decretos de desregulación de la actividad económica de 1991, que impactaron directamente en el sector agropecuario quebrando buena parte de las instituciones que sostenían políticas de apoyo a los productores, las cuales fueron desplazadas por nuevos organismos - que expresan nuevas conquistas del territorio inmaterial de la biotecnología - como la CONABIA (Comisión Nacional Asesora de Bioseguridad Aimentaria) y el INASE (Instituto Nacional de Semillas). En segundo lugar, la modificación del Reglamento de la ley de 1973, la ratificación del convenio UPOV '78, ocurrida en 1994, y la sanción de una nueva ley de patentes en 1995. Y por último, el que tal vez sea el hito más importante de la década: la resolución de la Secretaria de Agricultura, Ganadería y Pesca de 1996, que autorizó la introducción de la soja transgénica en el país, desencadenando un proceso de transformaciones territoriales de altísimo y duradero impacto, no sólo en Argentina sino también con repercusiones en países limítrofes como Brasil y Paraguay.

A partir de ese momento, y en un lapso sorprendentemente breve, la soja transgénica se convertirá en el cultivo predominante a nivel nacional, desplazando otro cultivos tradicionales y a la ganadería hacia áreas marginales, y convirtiéndose en el mascarón de proa del avance de nuevos actores económicos ligados al capital financiero y a las empresas semilleras-agroquímicas transnacionales por encima de formas de producción alternativas, fundamentalmente en las regiones extrapampeanas. Lo notable es que este violento proceso de desterritorialización de actores tradicionales y territorialización de nuevos agentes atravesó sin mayores inconvenientes el fin del patrón de acumulación de la convertibilidad —que establecía la paridad cambiaria entre el peso argentino y el dólar estadounidenseocurrida entre 2001 y 2002, el cual dio pie a una de las crisis políticas y sociales más graves de la historia nacional. Es más, con el advenimiento de un nuevo patrón de acumulación, basado en un tipo de cambio alto que reorienta el perfil productivo de la economía nacional hacia la exportación de commodities, la "sojización” del agro argentino encontrará condiciones inmejorables para expandirse.

La etapa posterior a la devaluación del peso es particularmente compleja para el análisis, ya que para caracterizarla es necesario tener en cuenta las continuidades y rupturas sociales, políticas y económicas con el período anterior, de clara hegemonía neoliberal. Como consecuencia de la bancarrota política del sistema de parti- 
dos, a partir del 2003 los gobiernos kirchneristas deberán reconstruir la gobernabilidad incorporando diversas demandas populares, alineándose en materia de política internacional con otros gobiernos progresistas como el de Lula da Silva en Brasil, y renovando la presencia estatal en la esfera económica como garante de un nuevo pacto social. Sin embargo, también deberán asegurar condiciones favorables para un nuevo ciclo de expansión económica en el que el proceso de extranjerización de las principales empresas nacionales, comenzado en la década previa, alcanzará niveles nunca antes vistos, alentado por la consolidación de actividades extractivas de gran impacto como la mega-minería metalífera, la industria forestal y la pesca, entre otras (Gaggero, Schorr y Wainer, 2014).

Las contradicciones de este esquema de conciliación de clases atravesarán períodos de latencia y otros de fuerte exposición. Un ejemplo de estos últimos, tal vez el más serio, ocurrió en 2008 con el conflicto alrededor de la Resolución nº 125 del ejecutivo nacional, que pretendía establecer retenciones móviles a las exportaciones de soja, un impuesto que buscaba aprovechar el alza internacional del precio de las materias primas. Las necesidades del Estado de contar con recursos fiscales para afrontar una política social expansiva que aliente el mercado interno mediante subsidios al consumo, hallaron una barrera infranqueable en el lock out y los agresivos cortes de ruta de los productores sojeros a lo largo y ancho del país, los cuales tuvieron un decisivo apoyo de los principales partidos de la oposición y de los sectores más conservadores de las clases medias urbanas. A partir de allí, el gobierno de Cristina Fernández se recuperará de esta derrota política con otras medidas progresivas y una retórica anti-oligárquica cada vez más fuerte, pero, con un accionar que podríamos asimilar al concepto de "hegemonía al revés” de Francisco Oliveira (2010), llevará adelante medidas favorables a la expansión del agronegocio, aún teniendo una política de contención hacia ciertos sectores que intentan instalar la agenda de la agricultura familiar.

Un primer momento de defensa de los intereses de la clase dominante local será la crisis con la multinacional Monsanto en 2010 a raíz de la denominada "bolsa blanca”, o sea aquellas semillas que luego de ser adquiridas por el productor, ya sea con o sin certificación, son reproducidas y circulan libremente sin regulación estatal ni reconocimiento sobre la propiedad intelectual sobre la variedad en cuestión, tal como se realiza tradicionalmente tanto en la agricultura capitalista como en la campesina. La empresa que desarrolló la soja RR resistente al Roundup (el agroquímico que ella misma produce), introducida en Argentina en 1996, permitió que ésta se expandiera sin ofrecer resistencia durante más de una década para imponer el paquete tecnológico que monopoliza, y sorpresivamente exigió que se le pagaran las regalías por el desarrollo de dicha variedad transgénica a todos los productores del país. De esta forma se revelaba la lógica más cruda de lo que implica el patentamiento de las semillas. En ese momento, el gobierno nacional defendió los intereses de los productores argentinos cuando el conflicto llegó a la Suprema Corte de Justicia de la Unión Europea, logrando que la exigencia de Monsanto fuera rechazada. Pero compensó a la corporación estadounidense aprobando la introducción de la soja INTACTA RR2 PRO en 2012; anunciando un acuerdo para construir una planta de desarrollo de semillas en la localidad cordobesa de Malvinas Argentinas; y reabriendo las negociaciones para sancionar una nueva Ley de Semillas coherente con las presiones que existían para la adhesión de Argentina al convenio UPOV '91 desde el año 2003 en adelante. 
Otro momento fue la publicación en 2011 del Plan Estratégico Agroalimentario 2011-2020 (PEA 2011-2020) que, al anunciar como meta a ser alcanzada para el 2020 los 160 millones de toneladas de granos producidos ampliando las hectáreas cultivadas, y al dedicar una atención casi nula a formas alternativas de producción, no hace más que legitimar y reforzar la territorialización del agronegocio en Argentina. La redacción del PEA 2011-2020 involucró la participación de universidades nacionales, cámaras empresarias y organizaciones rurales de todo el país, pero su carácter productivista levantó fuertes críticas incluso de parte de unidades académicas como la Facultad de Ciencias Agrarias de la Universidad Nacional de La Plata (Página /12, 16/4/2012) ${ }^{5}$.

Es importante mencionar también la presentación de un proyecto de ley sobre el uso de productos agroquímicos, realizada en septiembre de 2014 por parte de un diputado nacional de oficialismo, que apunta a reducir los marcos de revisión sanitaria de los productos químicos que se utilizan en la producción agrícola a gran escala; es decir, los célebres "insumos" que constituyen la principal fuente de ganancia de las grandes empresas que también pretenden controlar las variedades agrícolas a través del patentamiento de las semillas (El Zumbido, 10/11/2014) ${ }^{6}$.

En el año 2012 comenzaron las negociaciones para una nueva ley de semillas y creaciones fitogenéticas en el ámbito de la CONASE, con un anteproyecto que apuntaba a limitar el uso propio de las semillas, lo cual le granjeó el apoyo de las cámaras de empresas semilleras-agroquímicas y sus poderosos aparatos de propaganda, y le permitió acercar posiciones con los grandes productores y terratenientes, más dispuestos a negociar en aras de obtener un rol dominante en el nuevo esquema sin arriesgarse a presiones sorpresivas como las que sufrieron en el conflicto ocurrido en el año 2010. Pero también generó la oposición de los productores medianos (los chacareros nucleados en la Federación Agraria Argentina), mientras que los productores campesinos e indígenas ni siquiera estaban invitados a la mesa de discusión. La fisura en el bloque de intereses de las entidades que habían logrado con éxito oponerse a la Resolución n ${ }^{\circ} 125$ en 2008 (cuando la Sociedad Rural de la oligarquía tradicional, las Confederaciones Rurales Argentinas y la Confederación Intercooperativa Agropecuaria de los grandes productores capitalistas, y la Federación Agraria se aglutinaron en la autodenominada "Mesa de Enlace"), fue la causa principal de que la iniciativa fracasara, a lo que hay que sumarle la oposición de movimientos sociales afines al kirchnerismo que ocupan la Secretaría de Agricultura Familiar del Ministerio de Agricultura.

El debate sobre una nueva legislación que regule la producción, comercialización y fiscalización de las semillas se reavivó durante la primera mitad de 2014 con la presentación de un nuevo anteproyecto de ley por parte del Ministerio de Agricultura (Supercampo, 16/5/2014) . $^{7}$ El borrador que, no casualmente, fue hecho público en un encuentro del que participaron organizaciones de pequeños producto-

5 “Críticas al modelo extractivo”, Página /12, 16/4/2012. [Puesto en línea el 16 de abril de 2012. URL: http://www.pagina12.com.ar/diario/sociedad/3-191967-2012-04-16.html. Consultado el 2 de febrero de 2015].

6 “Agrotóxicos: una ley que retrocede”, El Zumbido, 10/11/2014. [Puesto en línea el 10 de noviembre de 2014. URL: http://www.zumbido.com.ar/2014/11/agrotoxicos-una-ley-que-retrocede/. Consultado el 10 de febrero de 2015].

7 "Presentaron el anteproyecto de la nueva Ley de Semillas”, Supercampo, 16/5/2014. [Puesto en línea el 16 de mayo de 2014. URL: http://supercampo.perfil.com/2014/05/presentaron-el-anteproyecto-de-la-nueva-ley-desemillas/. Consultado el 20 de enero de 2015]. 
res y movimientos campesinos afines al gobierno, consistía en un extenso articulado donde se pretenden congeniar intereses contrapuestos, siguiendo la premisa de la posible coexistencia entre agronegocio capitalista y agricultura familiar (Fernandes, 2008). Para empezar, ya en el primer artículo se señalaba como objetivo de la ley "proteger la propiedad intelectual de las creaciones fitogenéticas" (Ministerio de Agricultura de la Nación, Anteproyecto de Ley de Semillas y Creaciones Fitogenéticas - versión mayo 2014, p. 1) y al mismo tiempo contribuir a la "soberanía alimentaria”, una contradicción en sus propios términos, ya que a nivel internacional los movimientos que han creado la propuesta de la soberanía alimentaria —en contraposición al concepto de seguridad alimentaria- denuncian a los derechos de propiedad intelectual como uno de los mecanismos de ataque del agronegocio sobre la agricultura campesina (La Vía Campesina, 2013).

Más adelante, el proyecto de ley proponía distintos mecanismos de regulación a través de organismos público-privados como la CONASE, encargada de asesorar a la autoridad de aplicación de la ley, el Instituto Nacional de Semillas (INASE). En el texto, se proponía que la composición de la CONASE tenga una fuerte presencia de los obtentores de nuevas variedades fitogenéticas y las empresas semillerasagroquímicas, y con una curiosa adenda que solicita "la inclusión de un miembro de la agricultura familiar" (Anteproyecto de Ley de Semillas y Creaciones Fitogenéticas - versión mayo 2014, p. 3). A su vez, establecía un Registro Nacional de Usuarios de Semillas y otorgaba al INASE la facultad de prohibir la circulación de determinadas semillas si fuera necesario, habilitando incluso los decomisos de mercadería y la inhabilitación para comercializar; mientras tanto, el derecho de obtentor era ampliado a la producción, reproducción, propagación, venta, almacenamiento y canje de las semillas y sus productos; y es extendido a 20 años para granos y 25 años para vides, árboles frutales y ornamentales.

Las tensiones que atraviesan el proyecto político del gobierno nacional se expresaban en figuras como la del agricultor exceptuado, el cual debería estar presente en el Registro Nacional de Agricultura Familiar para no ser alcanzado por las atribuciones del derecho de obtentor, y en la propuesta, escasamente desarrollada y fundamentada en el texto del anteproyecto, de un "Sistema de Semillas para la Agricultura Familiar y Pueblos Originarios” que se encargaría de proteger las semillas nativas y criollas de este nuevo marco regulatorio con tintes policíacos. Estas adiciones resultaban una novedad frente al anteproyecto de ley que se había preparado en 2012, y no son otra cosa que un intento de franquear la oposición a esta iniciativa de sectores del oficialismo aglutinados alrededor de la Secretaría de Agricultura Familiar. Lo cierto es que la escasa o nula aplicación de leyes previas aprobadas en el Congreso Nacional, como la Ley de Bosques o la Ley de Emergencia Territorial, que apuntaban a proteger a las comunidades campesinas y aborígenes impidiendo el desmonte de la vegetación y prohibiendo los desalojos violentos, no sientan buenos precedentes para confiar en que esta nueva ley de semillas efectivamente proteja el patrimonio genético del país de las graves consecuencias de los sistemas de propiedad intelectual y patentamiento. Y aún confiando en las autoridades de aplicación de la nueva ley, es innegable que el hecho de que un derecho universal como el uso propio se convierta en objeto de una política focalizada para sectores vulnerables constituye en sí mismo un claro retroceso político y jurídico. Por otro lado, la sanción a fines de 2014 de una ley que declara de interés público a la agricultura familiar, campesina e indígena completa un cuadro 
que resulta contradictorio incluso para sectores que fueron parte del lock out de 2008 como la Federación Agraria (InfoPico, 15/2/2015) ${ }^{8}$.

En mayo de 2015 hubo un nuevo amague de avance de la nueva legislación privatizadora, cuando se anunció la inminente sanción de un Decreto de Necesidad y Urgencia del Poder Ejecutivo Nacional que regularía bajo nuevas bases el mercado de semillas argentino. La nueva medida pretendía congeniar el interés de los grandes productores de contar con la posibilidad de seguir acudiendo a la "bolsa blanca”, y de las empresas semilleras, a través de la creación de un fondo para el desarrollo de la biotecnología (Notas, 20/5/2015) ${ }^{9}$. El decreto nunca llegó a promulgarse, en parte debido a la presión de las propias cámaras empresariales agropecuarias. Sin embargo, poco tiempo después el secretario de Agricultura de la nación, Gabriel Delgado, anunció que el Poder Ejecutivo Nacional presentaría un proyecto de ley con el mismo contenido del decreto (Télam, 10/6/2015) ${ }^{10}$.

Dicho anteproyecto, que comenzó a circular durante la segunda mitad del 2015, es más escueto que el anterior, y apunta a conciliar los intereses de las grandes empresas semilleras con la de los grandes y medianos productores, sin prestar demasiada atención a la realidad de la agricultura familiar. Propone que todos los impuestos y regalías relacionadas al desarrollo biotecnológico sean pagados por única vez en el momento de compra de las semillas. Pero de esta manera restringe el uso propio del productor a las semillas adquiridas legalmente; es decir, ya sujetas a un mercado controlado por las corporaciones semilleras. Luego le brinda facultades extraordinarias al Ministerio de Agricultura para intervenir en el mercado de las semillas estableciendo pagos ulteriores en concepto de "aportes tecnológicos”, y permite al INASE ejercer un control fiscalizador sobre los usuarios de semillas. La novedad más importante es la propuesta de la creación del Fondo de Innovación Tecnológica para el Mejoramiento Genético (InnTeG), un fondo fiduciario para el fortalecimiento de la biotecnología nacional, con fuerte injerencia del sector privado (Biodiversidad en América Latina y el Caribe, 27/10/2015) ${ }^{11}$. A través de este borrador de ley se pueden notar los intentos del gobierno nacional de conciliar intereses contrapuestos en el seno de las clases dominantes, mientras busca contener las demandas de los sectores populares del sector agropecuario con políticas focalizadas. Un conflicto que será atravesado, pero perdurará, luego del recambio presidencial de diciembre de 2015.

8 “«El gobierno plantea leyes contradictorias», dicen desde la FAA”, InfoPico, 15/2/2015. [Puesto en línea el 15 de febrero de 2015. URL: http://www.infopico.com/politico/31741-el-gobierno-plantea-leyes-contradictoriasdicen-desde-faa. Consultado el 17 de febrero de 2015].

9 “El gobierno anunció una modificación de la Ley de Semillas por decreto”, Notas, 20/5/2015. [Puesto en línea el 20 de mayo de 2015. URL: http://notas.org.ar/2015/05/20/gobierno-modificacion-ley-semillas-decreto/. Consultado el 24 de agosto de 2015].

10 "Delgado anunció el envío de un proyecto de ley al Congreso para que los pagos por semillas se realicen solo al momento de la compra”, Télam, 10/6/2015. [Puesto en línea el 10 de junio de 2015. URL: http://www.telam.com.ar/notas/201506/108388-delgado-anuncio-el-envio-de-un-proyecto-de-ley-al-congresopara-que-los-pagos-por-semillas-se-realicen-solo-al-momento-de-la-compra.html. Consultado el 30 de octubre de 2015].

11 “Argentina: La pelea de Monsanto, los sojeros y las semilleras por una Nueva Ley de Semillas a su medida”, Biodiveridad en América Latina y el Caribe, 27/10/2015. [Puesto en línea el 27 de octubre de 2015. URL: http://www.biodiversidadla.org/Principal/Secciones/Campanas_y_Acciones/Argentina_La_pelea_de_Monsant o_los_sojeros_y_las_semilleras_por_una_Nueva_Ley_de_Semillas_a_su_medida. Consultado el 30 de octubre de 2015]. 
Resumiendo, el panorama argentino es coherente con el contexto latinoamericano de despliegue de nuevas estrategias del capital transnacional para penetrar las economías nacionales, contando con sectores importantes de la burguesía vernácula como aliados directos. Las últimas décadas han sido testigo de transformaciones territoriales en el agro argentino, tan profundas que no sólo han sobrevivido a la quiebra del patrón de acumulación de la convertibilidad, sino que se han acentuado durante la etapa neodesarrollista. El lock out patronal de 2008 fue un momento clave en este período, desde el momento en que aseguró el consenso ideológico alrededor del carácter inevitable e insuperable del esquema de los agronegocios, aún en un momento de impugnación del legado neoliberal de parte de sectores importantes de la sociedad (Konder, 2002). Esto no quita que surjan fuertes disputas por la apropiación de la renta en el bloque de sectores que han sostenido el avance del agronegocio en el país, obligando al Estado a buscar estrategias de conciliación de esos intereses.

Por otro lado, merece destacarse que hayan surgido numerosas expresiones de resistencia y cuestionamiento a las consecuencias sociales, económicas y ambientales más nefastas de este modelo tanto en áreas rurales como urbanas y periurbanas. Y que buena parte de esas novedosas experiencias políticas estén hoy enfrentando la posible sanción de esta nueva ley de semillas, redactada en favor de los intereses de las multinacionales semilleras-agroquímicas y los grandes productores agropecuarios.

\section{La oposición popular a la nueva Ley de Semillas: la búsqueda de alternati- vas, de la resistencia en el territorio a la disputa institucional}

Así como Argentina presenta similitudes con el contexto latinoamericano por el avance territorial e institucional del agronegocio, también lo hace por la presencia de crecientes expresiones de resistencia popular a las iniciativas privatizadoras y destructivas del capital transnacional y de las clases dominantes locales. El fenómeno político más importante ha sido el surgimiento de una nueva generación de movimientos campesinos, herederos de la experiencia de las Ligas Agrarias de la década del setenta, que ha afrontado el desafío de defender los intereses de buena parte de los sectores desplazados por el avance abiertamente violento del agronegocio, particularmente en las regiones históricamente periféricas del agro argentino. Estas organizaciones, relativamente jóvenes para la historia política argentina, han tomado la tarea de reagrupar a buena parte de los sectores populares del mundo rural que han sido desplazados por las transformaciones productivas y territoriales más recientes, ya sea porque han sufrido desalojos —u otro tipo de acciones desterritorializadoras directas - o porque se han convertido en "población redundante" para las nuevas estrategias de acumulación del capital; es decir, para el capital ya no ocupan ningún papel relevante en la producción de valor, ni como fuerza de trabajo ni como consumidores, y por lo tanto de no ser por estas organizaciones campesinas la única salida para ellos es abandonar el mundo rural. Una apuesta particularmente difícil en un país con una de las tasas de urbanización más alta del continente, y con una tradición de organización campesina e indígena de menor peso específico que en otros países de la región. 
Estos movimientos se han caracterizado por resignificar el concepto de campesino como una identidad política arraigada en prácticas productivas y saberes ancestrales, que sintetiza reivindicaciones de índole social como una justa distribución de la tierra y otras de carácter ambiental como la denuncia del monocultivo y del uso indiscriminado de los agroquímicos. Es también una identidad que se ha construido a distintas escalas, desde la local que le da sustento hasta la internacional que la enmarca en el cuadro general de las resistencias populares a la globalización neoliberal (Figurelli, 2013). Y es la identidad que se ha construido además en oposición al derrotero político de otras organizaciones gremiales del campo de origen popular, principalmente la Federación Agraria, en particular desde el conflicto del 2008, cuando dicha agrupación se ubicó junto a sus enemigos históricos de la Sociedad Rural.

Contemporáneamente, al calor del surgimiento de vigorosos procesos de oposición popular a distintas expresiones del extractivismo (principalmente la megaminería metalífera a cielo abierto), y con la participación de organizaciones políticas y sindicales que abrevan en la tradición del movimiento piquetero y el imaginario de la rebelión de diciembre de 2001, en distintas áreas urbanas se han generado notables iniciativas de denuncia y confrontación con las consecuencias ambientales y sanitarias del agronegocio. A diferencia de los movimientos campesinos, su accionar parte no desde el punto de vista productivo o estrictamente territorial, sino desde la problemática del espacio y la salud públicas, así como desde el rol de consumidores de los productos de la industria alimenticia (Fernandes, 2005). Otra característica importante es que, a diferencia de la mayoría de los movimientos campesinos, su origen es en las zonas centrales de la producción agropecuaria argentina, como la provincia de Buenos Aires o la de Santa Fe. La gran variedad de casos, inabarcable para los alcances de este trabajo, nos obliga a centrarnos en aquellos de mayor interés: el caso del Barrio Ituzaingó Anexo y de la localidad de Malvinas Argentinas, ambos en la provincia de Córdoba.

En el caso del Barrio Ituzaingó, un barrio periférico de la capital provincial literalmente rodeado de campos de soja transgénica, la altísima tasa de mortalidad y de incidencia del cáncer y otras enfermedades entre su población producto de la fumigación indiscriminada, llevó a la conformación del movimiento de las Madres de Ituzaingó, quienes en agosto de 2012 lograron, junto al apoyo de otros sectores como los Médicos de Pueblos Fumigados y la Campaña "Paren de Fumigarnos", que un productor agropecuario y un aerofumigador fueran condenados a tres años de prisión por el delito de contaminación. El poder judicial acabó reduciendo la pena al cumplimiento de tareas comunitarias, demostrando así su índole clasista, siempre favorable al mantenimiento de la dominación burguesa. Pero el hecho de que exista una condena penal sobre ciertas prácticas productivas impuestas por el agronegocio sentó un precedente inédito en el país y en el continente, útil para organizaciones y movimientos de otras latitudes, del carácter criminal que asume la acumulación capitalista en el marco de agronegocio (La Nación, 22/8/2012) ${ }^{12}$.

A escasos kilómetros del Barrio Ituzaingó, la localidad de Malvinas Argentinas se sacudió con el anuncio de la construcción de una planta de desarrollo y trata-

12 “Primera condena por fumigar con agroquímicos cerca de poblados”, La Nación, 22/8/2012. [Puesto en línea el 22 de agosto de 2012. URL: http://www.lanacion.com.ar/1501352-primera-condena-por-fumigar-conagroquimicos-cerca-de-poblados. Consultado el 23 de enero de 2015]. 
miento de semillas transgénicas de la corporación estadounidense Monsanto en agosto de 2012. El descontento con la medida se materializó en la creación de la Asamblea Malvinas Lucha por la Vida, la cual desde mediados de 2013 sostiene un acampe de bloqueo de la entrada al predio destinado a la construcción de la planta. Las sucesivas acciones represivas de parte del estado provincial no lograron frenar el crecimiento del apoyo popular a la Asamblea, que hasta el momento ha conseguido paralizar las obras de construcción.

Lo notable de este proceso de resistencia es la capacidad progresiva de articular demandas en distintos puntos del país, entre actores políticos de distinto origen. Un ejemplo se dio en la jornada de protesta ocurrida el 7 de junio de 2013 en el noreste de la provincia de San Luis, que incluyó el corte de una ruta provincial número 5. La medida de fuerza, encabezada por la Asociación de Campesinos del Valle del Conlara (ACVC) y acompañada por distintas organizaciones populares, tuvo como objeto denunciar la presencia en la región de Cresud, empresa perteneciente al grupo IRSA que compra y alquila campos para cultivar las semillas que Monsanto necesita desarrollar y tratar en Malvinas Argentinas y otras plantas del país. Dicha jornada fue un paso más en la lucha de la ACVC contra el avance del agronegocio en la región, que se expresa entre otras cosas en la mayor frecuencia de las fumigaciones sobre la población rural. Y una muestra de la potencialidad política de la articulación de demandas que enfrentan las distintas consecuencias sociales, territoriales y ambientales del agronegocio (Letercermonde, 27/6/2013) ${ }^{13}$.

La concepción del agronegocio como una expresión del extractivismo (en tanto una totalidad de múltiples manifestaciones con una lógica en común), construida lenta y contradictoriamente, es lo que permite trascender las reivindicaciones sectoriales para generar una verdadera respuesta contrahegemónica, capaz de repercutir en sectores cada vez más amplios de la sociedad. Esa capacidad de interpelación es la que obliga a sectores del establishment empresarial y sus think thanks a repensar estrategias de difusión de sus prácticas y productos, como lo demuestra el Congreso Maizar, organizado por la Asociación Maíz Argentino en julio de 2014, con el objetivo de "mejorar la comunicación”. Una crónica del congreso marca claramente el sentido del encuentro: "El congreso Maizar expuso el territorio de las próximas batallas de los agronegocios: la comunicación” (Periódico Mu, agosto 2014) ${ }^{14}$.

El repaso de estas experiencias tiene el objetivo de trazar los distintos recorrido políticos que hoy confluyen en las campañas de oposición a la posible sanción de la nueva Ley de Semillas. Las distintas iniciativas, la Campaña "No nos patenten la vida" 15 , la Campaña “No a la ley «Monsanto» de semillas" ${ }^{16}$ y la Campaña "Plantate: la vida no se negocia"17, reúnen un gran abanico de organizaciones sociales,

13 “Monsanto go home”, Letercermonde, 27/6/2013. [Puesto en línea el 27 de junio de 2013. URL: http://letercermonde.com/2013/06/27/monsanto-go-home/. Consultado el 27 de enero de 2015].

14 “Agromanipulite”, Periódico $M u$, agosto 2014, p. 8.

15 "No nos patenten la vida. Campaña contra la privatización de las semillas en Argentina.”, documento oficial de la campaña "No nos patenten la vida”, 4/9/2014. [Puesto en línea el 4 de septiembre de 2014. URL: http://nonospatentenlavida.org/documento/. Cosultado el 13 de febrero de 2015].

16 “Campaña NO a la nueva Ley «Monsanto» de Semillas en Argentina”, documento de la campaña "No a la nueva Ley «Monsanto»de Semillas en Argentina”, julio de 2014. [Puesto en línea el 2 de agosto de 2014. URL: $\quad$ http://www.opsur.org.ar/blog/2014/08/02/campana-no-a-la-nueva-ley-monsanto-de-semillas-enargentina/. Consultado el 9 de febrero de 2015].

17 "PLANTATE: LA VIDA NO SE NEGOCIA. La semilla en manos de los agricultores garantiza alimentos para todos.”, documento de la campaña "Plantate: la vida no se negocia”, 6/9/2014. [Puesto en línea el 6 de 
movimientos campesinos, cooperativas de pequeños productores, asambleas ciudadanas, medios de comunicación alternativos, partidos políticos y redes de consumidores e intelectuales. Más allá de algunas diferencias programáticas y tácticas entre sí, las campañas coinciden en denunciar los riesgos sociales y ambientales que implica la sanción y puesta en práctica del anteproyecto de ley que analizamos previamente. Defienden el derecho al uso propio de la semilla por parte de los productores y denuncian la política oficial de aprobación sistemática de eventos transgénicos sin control de sus consecuencias, así como la propuesta del PEA 20112020. Además, se desmarcan de la estrategia de acercamiento al gobierno nacional de organizaciones como el Movimiento Nacional Campesino Indígena, señalando las contradicciones del anteproyecto alrededor de la posible convivencia del agronegocio y la agricultura familiar que se expresa en el texto a través del régimen especial de excepción para las semillas criollas y nativas.

La búsqueda de incidir en la discusión sobre la nueva ley en el ámbito del Estado por parte de los organizadores de estas campañas llevó a la realización de una Jornada de debate en el Congreso de la Nación el 17 de noviembre de 2014. Con el título de “Leyes de semillas y modelo productivo en Argentina”, la convocatoria estuvo presidida formalmente por diputados nacionales del bloque opositor de la Unidad Popular, y reunió a representantes de los distintos miembros de las campañas, quienes disertaron sobre tres ejes: "Las semillas dentro del modelo agrario hegemónico”, “Las semillas como bienes comunes”, y "La propiedad intelectual de las semillas”. Fue una ocasión para poner en juego el capital político acumulado por los sectores que sostienen las campañas, proyectando las experiencias de lucha a lo largo de todo el país al plano de la disputa institucional. Sin embargo, la ausencia en el debate de representantes del oficialismo, de los sectores que impulsan la nueva ley, y de las organizaciones sociales que apoyan la política gubernamental en materia de agricultura familiar, obliga a redoblar esfuerzos para hacer llegar estas perspectivas críticas a una confrontación real con quienes manejan los principales resortes del poder estatal.

\section{Algunas reflexiones finales}

"Si es aniquilado un pueblo o un Estado o incluso un determinado grupo de gente, que - por el hecho de ocupar una porción del mundo que nadie puede duplicar sin más- presentan una visión del mismo que sólo ellos pueden hacer realidad, no muere únicamente un pueblo o un Estado o mucha gente, sino una parte del mundo - un aspecto de él que habiéndose mostrado antes ahora no podrá mostrarse de nuevo- . Por eso la aniquilación no es solamente del mundo sino que también afecta al aniquilador. La política, en sentido estricto, no tiene tanto que ver con los hombres como con el mundo que surge entre ellos; en la medida en la que en que se convierte en destructiva y ocasiona la ruina de éste, se destruye y aniquila a sí misma. Dicho de otro modo: cuantos más pueblos haya en el mundo, vinculados entre ellos de una u otra manera, más mundo se formará entre ellos y 
más rico será el mundo. Cuantos más puntos de vista haya en un pueblo, desde los que mirar un mundo que alberga y subyace a todos por igual, más importante y abierta será la nación. Si por el contrario aconteciera que a causa de una enorme catástrofe restara un solo pueblo sobre la Tierra en que todos lo vieran y comprendieran todo desde la misma perspectiva y vivieran en completa unanimidad, entonces el mundo en el sentido histórico-político llegaría a su fin (...). Dicho con otras palabras: sólo puede haber hombres en el sentido auténtico del término donde hay mundo y sólo hay mundo en el sentido auténtico del término donde la pluralidad del género humano es algo más que la multiplicación de individuos de la misma especie."

Hannah Arendt (1997: 117-118)

El estudio del panorama latinoamericano general permite aventurar algunas impresiones sobre la actualidad argentina, en la que la disputa sobre una nueva Ley de Semillas es el capítulo más reciente de una batalla de largo alcance entre proyectos contrapuestos de país, entre formas opuestas de entender la agricultura, de relacionar la producción de riqueza económica con el respeto por los bienes naturales; en definitiva, de producir espacio y territorializarse. En primera instancia, es necesario tener en cuenta la gran complejidad del panorama político de la región y del país luego de la crisis del proyecto neoliberal que había hegemonizado el período posterior a las dictaduras de la época de la Guerra Fría, en el que encontramos distintos grados de ruptura e impugnación del orden social previo; un marco inédito de alza sostenida del precio de las materias primas en el mercado internacional, que empuja hacia la reprimarización de las economías nacionales; fuertes reconfiguraciones del sistema de partidos de varios países; la irrupción de nuevos actores sociales de carácter popular; y nuevas formas de injerencia del imperialismo y el capital transnacional.

En segundo lugar, es preciso dar cuenta de la influencia que han tenido los regímenes de propiedad intelectual y la biotecnología para la difusión de nuevas variedades transgénicas controladas por las empresas semilleras-agroquímicas en el agro argentino. Se dijo en este trabajo que ambos constituyen un territorio inmaterial del agronegocio, pues han fortalecido en el plano legal, institucional y del conocimiento la territorialización de las relaciones de producción del agronegocio en la estructura productiva del agro argentino. La posibilidad de una nueva ley de semillas, como sucede con las iniciativas similares en otros países de la región, implica un despliegue ulterior de estas estrategias privatizadoras. No obstante, es importante señalar que las idas y vueltas del anteproyecto de ley, así como las contradicciones que presenta el texto del anteproyecto en su versión del año 2014, reflejan una correlación de fuerzas sociales compleja, en particular en las tensiones que atraviesan la base social y política del gobierno nacional.

También es relevante el hecho de que este territorio inmaterial ha sido uno de los objetos de disputa que ha tomado la resistencia al agronegocio para fortalecerse. Con hitos como la investigación del biólogo Andrés Carrasco sobre los efectos del glifosato en los tejidos vivos publicada en 2009, que brindó argumentos de denuncia a numerosas organizaciones, y provocó una reacción de descrédito y persecución incluso desde el Ministerio de Ciencia y Tecnología de la Nación, la defensa de formas alternativas de producción agrícola más justas ambiental y socialmente ha podido tener una prédica hacia sectores cada vez más amplios, aún en 
aquellos que no sufren directamente las consecuencias más terribles de este proyecto excluyente.

Claro está que la capacidad de capitalizar políticamente estos debates políticos e ideológicos está dada por el nivel de movilización y la audacia de la acción directa: ya sea en la defensa del territorio de las comunidades campesinas y aborígenes, en los cortes de ruta y otras vías de circulación de los flujos de mercancías, o en las protestas y manifestaciones en los grandes centros urbanos, será fundamental alcanzar estadios superiores de organización y capacidad de intervención en la esfera pública. De todos modos, sería contraproducente pretender jerarquizar un plano del accionar político por sobre el otro, ya que la riqueza de estrategias de acción directa y de debate ideológico es la clave del porvenir exitoso o no de estos sectores. Además, las experiencias latinoamericanas reseñadas al principio marcan la importancia de lograr una interpelación de la sociedad en su conjunto para enfrentar la sanción de una nueva ley de semillas que consagre el patentamiento del patrimonio genético del país; es decir, de la capacidad de construir una hegemonía en la que la defensa de la agricultura campesina y la soberanía alimentaria equivalga a la defensa del interés general de la sociedad, escapando a los riesgos de encasillamiento y aislamiento en públicos específicos y acotados que entraña el uso de las nuevas tecnologías de la comunicación (Tilly y Lesley, 2010). Y esa construcción de hegemonía estará determinada en gran medida por la capacidad de apuntalar no sólo una resistencia, sino un proyecto alternativo, ya no simplemente de oposición a una nueva ley, sino también de reemplazo de la ley vigente desde 1973. En una coyuntura de recambio presidencial para fines de 2015, que cierra un ciclo político hegemonizado por el kirchnerismo con un marcado giro conservador, será necesario para las organizaciones populares intervenir en un panorama de reacomodamiento de los distintos sectores de poder. Y, en el mismo sentido, será clave aprovechar las ocasiones en las que se produzcan conflictos de intereses en el propio seno de las clases dominantes, como lo muestra la disputa alrededor de la cosecha de soja del verano austral 2015-2016, en el que los gremios de acopiadores de granos son presionados por Monsanto para ejercer el cobro de las regalías del uso de la soja Intacta a los productores, generando una disputa judicial que pone trabas a la circulación de la producción sojera para el futuro inmediato (La Nación, 14/10/2015) ${ }^{18}$.

No se trata de una tarea sencilla: hay intereses económicos y políticos gigantescos por detrás que deben ser enfrentados. Pero el riesgo de permitir el patentamiento de las especies de importancia agrícola, aún con los regímenes de excepción más inclusivos posibles, es el riesgo de perder lentamente la riqueza genética de las variedades criollas, y la riqueza social que las generó. Tal como decía Hannah Arendt, es permitir que el mundo, que la sociedad y su relación con la naturaleza, se haga más pobre.

\section{Bibliografía}

Arendt, Hannah (1997) ¿Qué es la política? Barcelona: Ediciones Paidós.

18 “Crece la puja por el pago de regalías de la soja”, La Nación, 14/10/2015. [Puesto en línea el 14 de octubre de 2015. URL: http://www.lanacion.com.ar/1836257-crece-la-puja-por-el-pago-de-regalias-de-la-soja. Consultado el 22 de octubre de 2015]. 
Fernandes, Bernardo Mançano (2005) "Movimentos socioterritoriais e movimentos socioespaciais: contribuição teórica para uma leitura geográfica dos movimentos sociais”. Revista NERA, núm. 6, 14-34.

Fernandes, Bernardo Mançano (2008) “Entrando nos territórios do Território”, en E. P. Paulino y J. E. Fabrini (orgs.) Campesinato e Território em disputas. São Paulo: Expressão Popular, 273-301.

Fernandes, Bernardo Mançano (2009) “Sobre a tipologia de territórios”, en M. A. Saquet y E. S. Sposito (orgs.) Territórios e Territorialidades. São Paulo: Expressão Popular, 197215.

Figurelli, María Fernanda (2013) Movimientos populares agrarios. Asimetrías, disputas y entrelazamientos en la construcción de lo campesino. (Working Paper Series, núm. 48). Berlin: International Research Network on Independent Inequalities in Latin America.

Gaggero, Alejandro; Schorr, Martín, y Wainer, Andrés (2014) Restricción eterna: el poder económico durante el kirchnerismo. Buenos Aires: Futuro Anterior Ediciones.

Harvey, David (2005a) “El «nuevo» imperialismo: acumulación por desposesión”, en Socialist register 2004. Buenos Aires: CLACSO, 99-129.

Harvey, David (2005b) "El arte de la renta: la globalización y la mercantilización de la cultura”, en D. Harvey y N. Smith (eds.) Capital financiero, propiedad inmobiliaria y cultura. Barcelona: Universidad Autónoma de Barcelona, 29-57.

Konder, Leandro (2002) A questão da Ideologia. São Paulo: Companhia das Letras.

La Vía Campesina (2013) La Vía Campesina: Nuestras semillas, nuestro futuro. (Cuadernos de La Vía Campesina, núm. 6). Jakarta: C.S. Fund/Programa FOCAD/Fondo Internacional para Amplificar Soluciones Agroecológicas.

Ministerio de Agricultura de la Nación (2014) Anteproyecto de Ley de Semillas y Creaciones Fitogenéticas - versión mayo 2014.

Montecinos, Camila; Vélez, Germán, y Rodríguez Cervantes, Silvia (comps.) (2014) Leyes de semillas y otros pesares: los pueblos de América Latina las cuestionan e impugnan. Marcos Paz: Acción por la Biodiversidad.

Oliveira, Francisco (2010) Hegemonia às avessas. São Paulo: Boitempo.

Perelmuter, Tamara (2013) "El rol de la propiedad intelectual en los actuales procesos de cercamientos. El caso de las semillas en la Argentina”, en N. Giarracca y M. Teubal (comps.) Actividades extractivas en expansión ¿Reprimarización de la economía argentina? Buenos Aires: Ed. Antropofagia, 97-118.

Perelmuter, Tamara (2014) “Conocimiento, semillas y propiedad. El debate actual en Argentina en torno a la modificación de la Ley de Semillas”. IX Congreso de la Asociación Latinoamericana de Sociología Rural "Sociedades Rurales latinoamericanas. Diversidades, contrates y alternativas”. Ciudad de México, 6 al 11 de octubre de 2014.

Tilly, Charles, y Wood, Lesley J. (2010) Movimientos sociales 1768-2008: desde de sus orígenes a Facebook. Barcelona: Editorial Crítica. 